\begin{tabular}{|c|cc|c|}
\hline & PORT SAID ENGINEERING RESEARCH JOURNAL \\
Faculty of Engineering - Port Said University \\
Volume (20)
\end{tabular}

\title{
Effect of Façade's Segments Formation on Noise Propagation in Urban Streets
}

\author{
Sara G. Eltarabily ${ }^{1}$, Ashraf Elmokadem², Mostafa R. Ismail ${ }^{3}$
}

\begin{abstract}
Façades as a part of urban areas' components; play an important role in sound propagation which affect sound environment in a street canyon. A parametric study was performed in order to investigate the influence of façade's formation by segments ratio on sound fields in urban streets in terms of sound pressure level (SPL). A computer simulation technique based on a hybrid method combining ray tracing and image source modeling was adopted, and an omnidirectional sound source was used. Series of computer simulations of varied numbers of segments that form façades were investigated in order to evaluate the real effect of the diffusion reflections that happened by façades with formations; relative to the smooth façades on sound propagation in streets. Results, in terms of relative sound pressure levels, show that a positive effect can be observed in the reduction of sound levels.
\end{abstract}

\section{INTRODUCTION}

\subsection{Sources of environmental noise}

Environmental noise is considered a part of community noise, which is defined as noise emitted from all sources. The European Union (EU) Directive [1] on the management of environmental noise defines environmental noise as unwanted sound; also noise is any sound that is of random mix of frequencies.

In our surroundings, there are different sources emitting various types of environmental noise that can affect a community[2], namely; noise from: industry, transportation, construction sites, and from residential and leisure areas; according to (WHO) World Health Organization reports.

Transportation noise is the main source of environmental noise pollution, including road traffic, rail traffic and air traffic. As a general rule, larger and heavier vehicles emit more noise than smaller and lighter vehicles. The basics of outdoor sound propagation, and the calculation of noise levels; requires knowing transportation sources types; such as (point source- line source):

- Point source: A sound source can be considered as a point source, if its dimensions are small in relation to

1 Architecture and Urban Planning Department, Faculty of Engineering, Port Said University, Port Said, Egypt, Email: saraeltarabily@gmail.com

2 Architecture and Urban Planning Department, Faculty of Engineering, Port Said University, Port Said, Egypt, Email: elmokadem1@gmail.com

3 Architecture Department, Faculty of Engineering, Ain Shams University, Cairo, Egypt, Email:

mostafa_ismail@eng.asu.edu.eg the distance to the receiver and it radiates an equal amount of energy in all directions. Typical point sources are industrial plants, aircraft and individual road vehicle. The sound pressure level decreases $6 \mathrm{~dB}$ whenever the distance to a point source is doubled (in the free field) [3].

- Line source: A line source may be continuous radiation, such as from a pipe carrying turbulent fluid, or may be composed of a large number of point sources so closely spaced that their emission may be considered as emanating from a notional line connecting them. The sound pressure level decreases $3 \mathrm{~dB}$, whenever the distance to a line source is doubled [3].

\subsection{Health effect of noise exposure}

The relation between environmental noise and human health is an important issue, because of its effect on the quality of life.

Most studies results strongly indicate that the health of the urban population is at risk by the presence of noise, when noise causes both physiological and psychological symptoms in people exposed to it. In extreme cases, victims can be driven to suicide and assault due to aggravation [4] [5] [6].

Adverse health effects of noise have been classified as shown in Figure 1 according to nine health indexes symptomatic of noise pollution to: (Noise-induced hearing impairment, Interference with speech communication, Disturbance of rest and sleep, 
psychological, mental-health and performance effects, Effects on residential behavior and annoyance, As well as interference with intended tasks and activities, Property damage, Vascular constriction, Friendship formation and/or maintenance), with the aid of these indexes the environment can be evaluated.

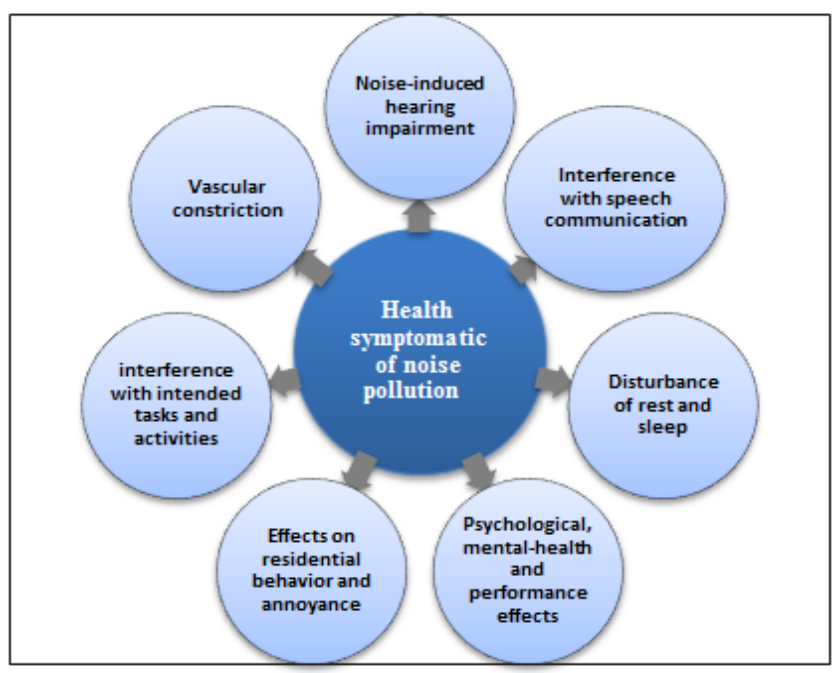

Figure 1- Health symptomatic of noise pollution [Source: by researcher, B. Berglund, Guidelines for community noise]

\subsection{Noise propagation in urban environment}

There was a relationship between spatial distribution of noise pollution and urban features; street width and building height, construction density, the existence of open spaces, and the shape and position of buildings [7]. Therefore, research has been conducted to reduce urban noises.

Urban form can be defined as the spatial pattern of human activities at a certain point in time. The conception of urban typologies refers to the arrangement, appearance and functionality of the building and especially to the concept and usage of the urban space [8]. When urban morphology is regular, a positive correlation between the total noise pollution and the street width to building height ratio is more evident.

The direct correlation between urban form and façade noise levels was investigated in a previous study [9], resulted that with increasing form index the average values of $L_{e q}$ also increase, this is explained by the fact that the greater the compactness of the urban form more exposed are the buildings facades, and this is also due to the fact that the greater the regularity of urban forms, the lower is the possibility of formation of shadow zones, that is more protected areas.

In previous study [10]; The effect of number of floors of façade as an indicator of urban form on façade noise levels was studied in three different types of urban forms with nine scenarios, that were presented in concavities, convexities, and absence of salience urban form. The results showed a small decrease of Leq max $_{\text {and average }}$ Leq with increasing number of floors. In the case of Leq $_{\text {min }}$, this trend is reversed.

Compactness of urban form refers to a form without irregularities, so it is not allowing the presence of protected area or shadow zones. The effect of compactness (CI) index of urban form on noise levels was studied in previous work [8] with various scenarios for ten urban forms, which including all saliencies of all urban forms. The results showed that, with the increase of the CI index, the average noise level on the facades of the buildings increases.

The existence of discontinuities between the neighboring façades of buildings can render the space permeable to noise, contributing to the lower persistence and concentration of reflected sound [10]. With increasing permeability index, the average values of Leq also increase, this is explained by the fact that the greater the permeability of the urban form is the sound waves more easily are able to reach the buildings inside.

The ratio of open space (ROS) index is a one of urban form indicators affects noise levels, ROS index refers to the proportion of open space, compared to the total urban area, it was studied previously [8] in order to be considered as an acoustical tool for new building constructions. It is possible to say that with the increase of ROS index, the voids between buildings also increase, that is, increases the space for propagation of sound waves reducing quiet areas. As expected, the result is with the increase of ROS index, the average noise level on the facades of buildings increases.

Providing easy access to nearby green areas in urban environments can enhance the process of healthy planning. The effect of availability to nearby green areas on perception of noise in a quiet side; as an aspect of urban residents' well-being was examined in a previous paper [11]. Comparison between two noise-conditions groups (noise/noise - noise/quiet) for both with and without access to a quiet side; was investigated. Results 
showed that better availability to green areas is important for residents' well-being by reducing long-term noise annoyances than poorer one.

Natural materials including green roof systems, green walls, and vegetation in urban areas can reduce noise levels and reverberation in urban spaces [12]. Also wellplanned arrangements of trees - like sonic crystals effects - can lead to the reduction in transmitted sound more than $15 \mathrm{~dB}$ by scattering of trunks and branches, when they arranged in periodic arrays and at midfrequencies around $1 \mathrm{kHz}$ [13].

The screen effect of using the arrangement of trees in streets was modeled in a previous study [14], that suggested to using trees as a possible noise control method. The trees were assumed as "screens" aligned in the same direction as the facades and which scatter the sound in all directions. The results of modeling by using "Markov chain" method were compared with the results obtained with commercial software - "Raynoise"- model in order to predict sound levels for street containing trees relative to that in unscreened case. The results of sound reductions in a street, that containing trees with dense leaves, and absorbent building façades, are typically less than $1.5 \mathrm{~dB}$, so the trees as screens have only a slight effect on sound attenuation.

Kang has also suggested that diffusely reflecting façades and scattering objects including: trees, street furniture, etc. may be possible noise control method in streets [15].

In order to investigate the effect of buildings arrangement on sound propagation in urban spaces; Picaut \& Simon [16] presented a numerical simulation model for a periodic network of hexagonal buildings. The results showed that the noise in simulated urban areas has a diffusing feature, and that the geometrical disposition of the buildings in the built-up area, and the roughness of the building facades are sufficient to ensure such a behavior.

The effect of four parameters (buildings density- ground floor dimensions of buildings- buildings height- façade absorption characteristics) on noise propagation through urban fabric was investigated in a previous paper [17]. The sound propagation through an array of simple buildings blocks in a very regular street configuration was modeled, assuming buildings façades to be diffuse surfaces, and interchange of energy occurs between faces. The results showed that there is a decrease in far field noise levels by increasing buildings density, and by increasing floor area dimensions; due to the effect of occlusion that resulted from buildings density.

About the influence of buildings roof shape on sound propagation, it can be considered as an important means to limit sound pressure levels at non-directly exposed façades in a quiet side. Using roof shape as a noise shielding were analyzed [18], several diffraction edges can be happened when sound propagates over roofs, results showed that with increasing vehicle velocity, the influence of roof slope angle on shielding becomes more important, and the height of the roof top is clearly not a good indicator of shielding efficiency.

Regarding the relation between urban building coverage and noise levels in indoor spaces by traffic, and the spatial sound level on façades for indoor sound environment, surprisingly, Building Plan Area Fraction has significant positive relations to the spatial sound levels on noisy façades, which indicates that there is a big potential that a site with a higher building coverage have more noisy indoor spaces.

Streets lined with high building on both sides, which form a semi- enclosed space where sound levels can increase and noise levels can become inadmissible. Complete Aspect Ratio and Building Frontal Area Index play important roles on the spatial sound level attenuation in outdoor open areas; Distance of First-row Building to Road and Building Frontal Area Index are the two important parameters for outdoor noisy open area reduction [19].

In previous studies about the relation between façade's height and urban noise, when the number of floors increased, the extent of the most exposed façade also increased, increased the average and maximum $\mathrm{L}_{\mathrm{eq}}$. In contrast, with increasing the size of the protected area, it is causing a reduction in the minimum $L_{\text {eq }}$ [19] [20].

The buildings structures in the street canyon effect on sound levels, noise in the street can be reflected to the street by building's formations like; balcony fronts, increasing the noise even more. Diffusers can be used on these balcony fronts to reduce the noise reflected back down to the street.

A numerical study of the use of acoustic diffusers to reduce noise has been carried out to characterize the diffusers [21], which shows that the maximum diffusion 
coefficient is around 0.5 on the frequency range [500$1400 \mathrm{~Hz}$ ] and seems well adapted to reduce road traffic noise.

The influence of façade's details formation on the sound field in a street canyon was studied in a past work [22]. Measurements of the relative sound pressure level distribution in the detailed façade model, and a boxmodel were compared in function of the distance from the center of the street. The comparison resulted that the use of an inspiration façade diffusers - a grid-like texture - as a transparent skin placed in front of flat facades lead to a stronger decrease of the sound pressure level relative to the box-model with distance from the source at certain frequencies $(250 \mathrm{~Hz}-500 \mathrm{~Hz})$.

In this paper, therefore, the propagation of sound in urban streets is investigated with a range of number of segments that form façades. The purpose of this study is to provide an overview of the sound fields in a single urban street. It was expected that the reflected sounds from façades would play a significant role in the sound fields in urban streets and the acoustical characteristics of the single street would be different according to formation by number of segments. The sound fields were predicted using a software package based on image source method and ray tracing technique. Computer simulations were validated by comparisons with experimental studies [23] [24]. Relative Sound pressure level was then obtained from the simulations while segments vary from different numbers of vertical segments formations.

\section{METHOD}

Using computer simulation, a parametric study was carried out in a single urban street in order to systematically explore the influence of formation by number of segments on the sound fields. The segments number varies with vertical protrusions, representing impact of façade's formation.

\subsection{Simulation model}

The main case configuration used in this study is shown in Figure 2. The model of the urban street consists of three surfaces; two parallel façades and the ground surface. The upper side and street ends are open sky with completely absorbent. The buildings were continuous along a street at constant height $(36 \mathrm{~m})$ that was derived from one of Egyptian's urban street configurations which corresponds to the standard height from floor to next floor $(3 \mathrm{~m})$.

The street length was $(100 \mathrm{~m})$ with recommended width as $(24 \mathrm{~m})$ for a main street; the height to width ratio $(\mathrm{H} / \mathrm{W})=1.5$.

Omnidirectional point source (A0) was located around the middle of urban street: $x=5 \mathrm{~m}, \mathrm{y}=12 \mathrm{~m}$, and the height of the point source was $1.0 \mathrm{~m}$. Fifteen receivers were located around the middle of the street in the range of $\mathrm{x}=25 \mathrm{~m}$ and $\mathrm{x}=95 \mathrm{~m}$ along a direction length. The distances between receivers in $\mathrm{x}$ direction were $5 \mathrm{~m}$ per a step, and the heights of the receivers were $1.5 \mathrm{~m}$.

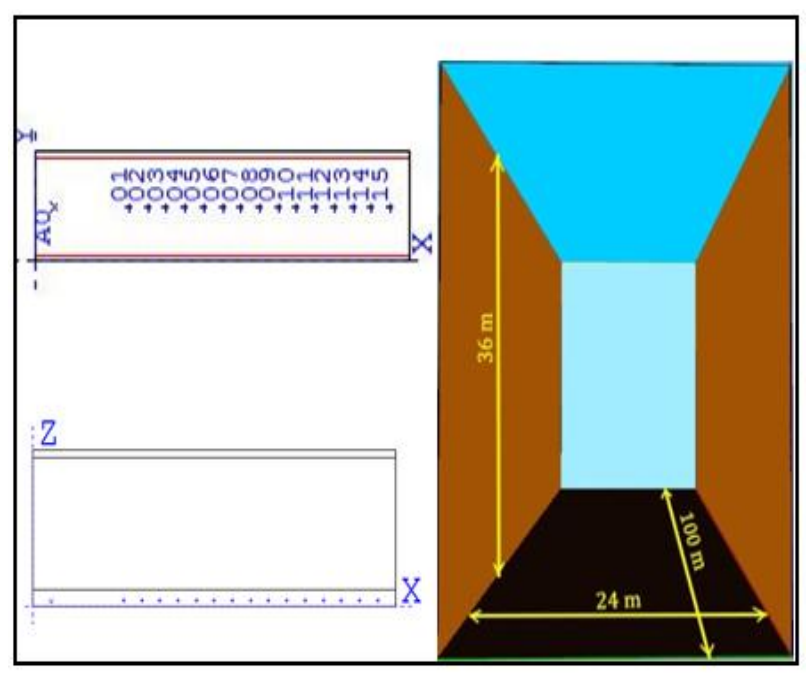

Figure 2- Main case configuration [Source: researcher]

Dividing façade's surface into rhythmic vertical segments along street's length is the main geometric aspect of the models of case studies. The formation based on divided segments' ratio and by protrusions on the two façades that act like diffusers array in true and false order along the single street.

As listed in Table 1, the segments were changed to odd and even cases with $(1.25 \mathrm{~m})$ depth when the width of one façade was fixed to $10 \mathrm{~m}$, and fixed maximum height to $36 \mathrm{~m}$. Arrangement of vertical segments was presented with number of segments $(\mathrm{N})$; its range varied from $\mathrm{N}=2$ to $\mathrm{N}=10$ which formed one façade with width $=10 \mathrm{~m}$ and repeated ten times along the $100 \mathrm{~m}$ of the street's length. One can notice that in case of segments $\mathrm{N}=3, \mathrm{~N}=4$ the one façade formation has two vertical (break-out) protrusions with different width, and also that in case of segments $\mathrm{N}=5, \mathrm{~N}=6$ the one façade formation has three 
vertical (break-out) protrusions with different width, and thus in $\mathrm{N}=7,8$ has four protrusions and $\mathrm{N}=9,10$ has five protrusions.

Table 1- Configuration of vertical segments cases [Source: researcher]

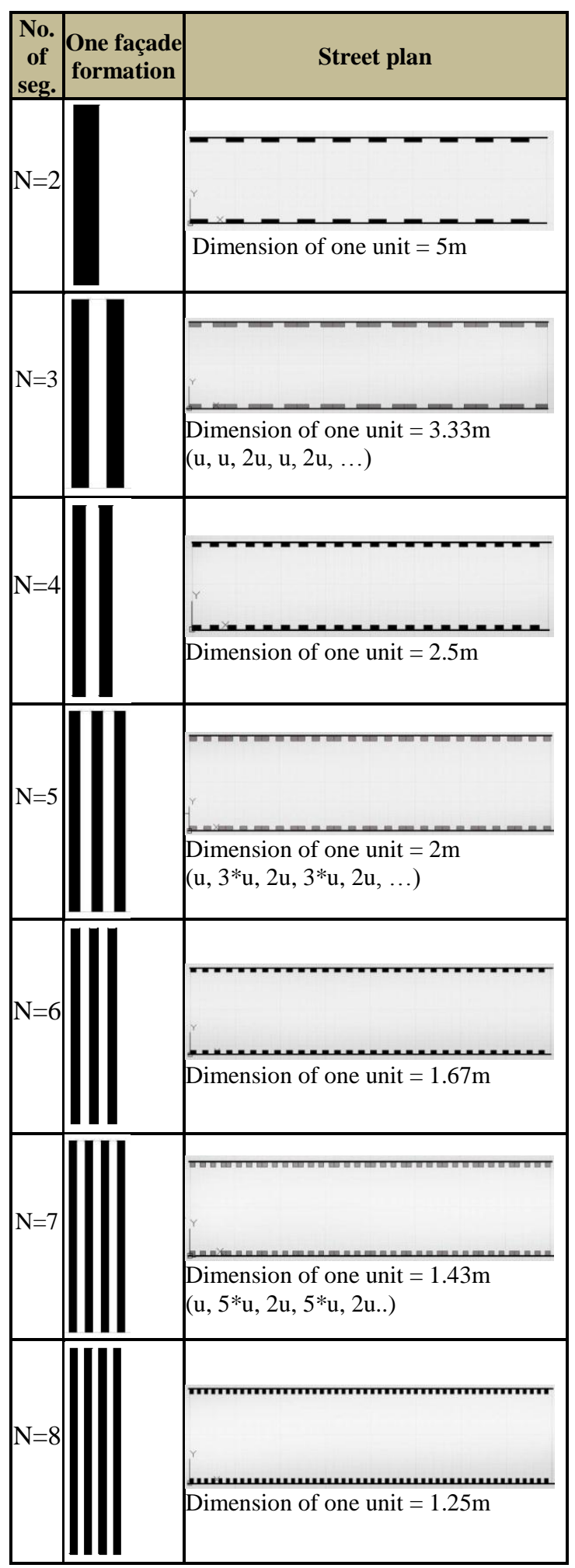

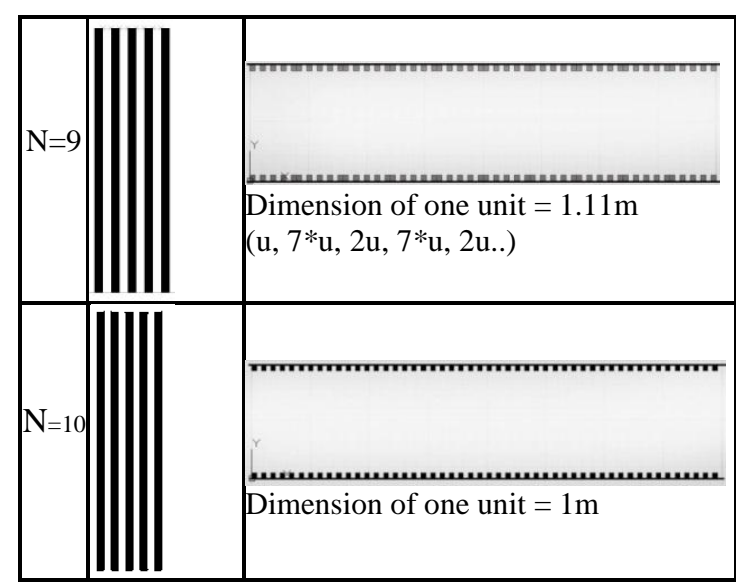

\subsection{Acoustical parameters}

Previous studied [15] [20-24] focused on sound attenuation and reverberation in urban streets in terms of steady-state sound pressure level (SPL). Consequently, relative (SPL) was also analysed in the present study. Only the results at $1 \mathrm{KHz}$ were presented because the absorpsions of the facades were uniform over the frequency range, and it included the traffic noise frequency range. Absorption coefficients were varied from low to high values $(0.1,0.3,0.5)$ in order to test the feasibility of increasing the absorption values in sound attenuation along street. The ground was assumed to be smooth reflector with absorption coefficient (0).

\subsection{Simulation method}

Acoustic software package CATT-Acoustic version 8.0 was used to model the urban streets. For point sources, a hybrid calculation method combining the image source method (ISM) for detailed early reflections with a raytracing method for the late part of the response was used. Simulations were performed by setting the specular reflection order $=3$, by using 20000 rays/octave, and ignored changing acoustic environment data because it has no effect in relative (SPL) cases.

\section{RESULTS AND DISCUSSIONS}

\subsection{Sound attenuation along the length}

Comparisons of the relative sound pressure level at (1 $\mathrm{KHz}$, where Absorption co.= 0.1) in the varied façade's segments models in function of the distance from the beginning of the street were shown in Figure 3 to Figure 6. Inittially, Formation by façade's segments result in more sound attenuation along the street length, and some of the sound attenuation curves are smooth concave, 
indicating that the sound attenuation becomes more with the increase of source-receiver distance.

However, significant differences between number of segments were also found. The SPL attenuation at reciever distance $=80 \mathrm{~m}$ for the $\mathrm{N}=4$ segments is $(-8 \mathrm{~dB})$ greater than the SPL attenuation at reciever distance $=80$ $m$ with other even numbers of segments, also the relative SPL trends for $\mathrm{N}=4$, and $\mathrm{N}=8$ are gradually descended. For the segments $\mathrm{N}=2,6,10$ the relative SPL are less than those for other even numbers of segments, and its trends are disordered every $5 \mathrm{~m}$.

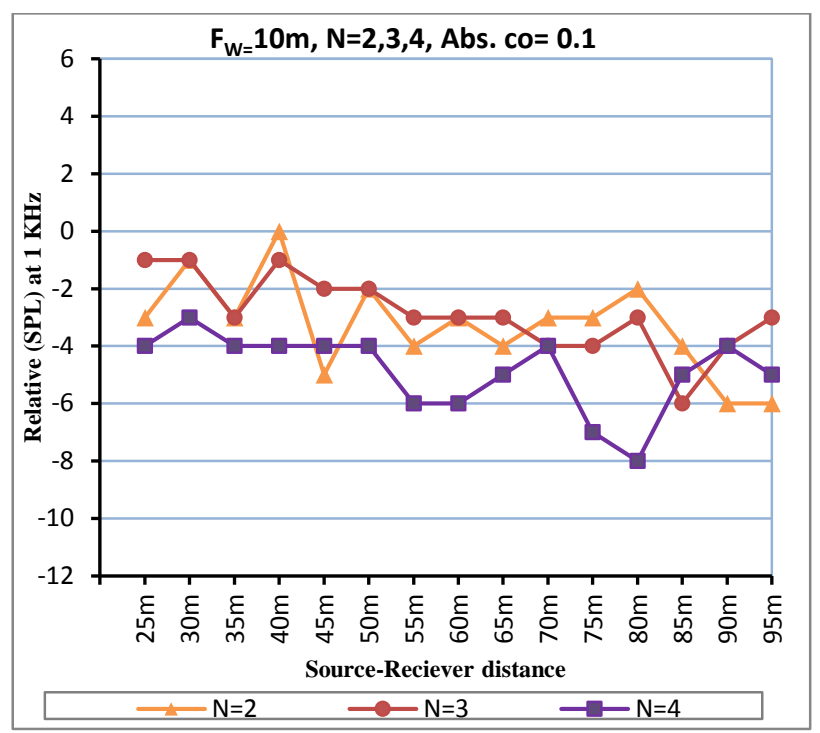

Figure 3- Comparison between relative SPL in N=2,3,4 cases of façade's segments (two protrusions) [Source: researcher]

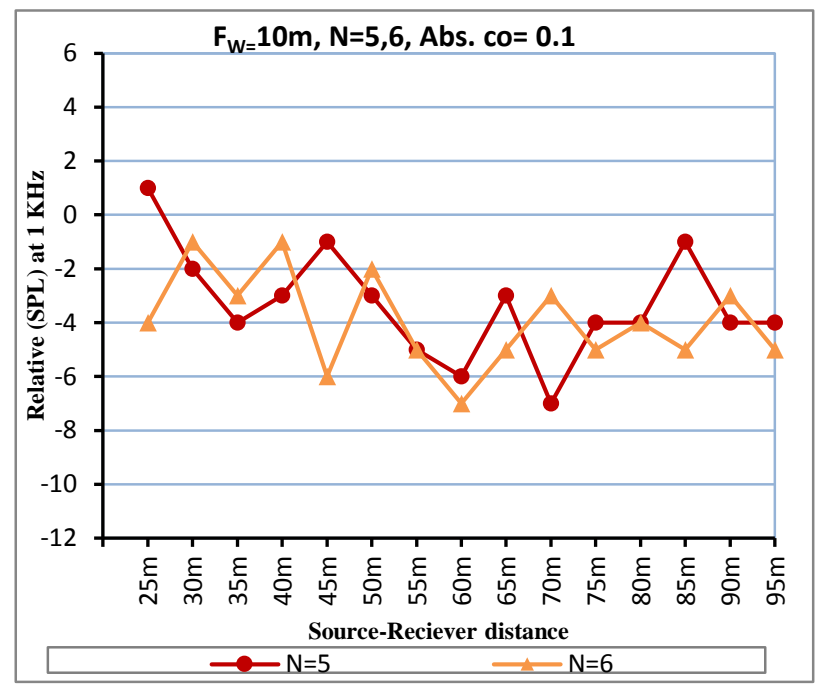

Figure 4 - Comparison between relative SPL in $N=5,6$ cases of façade's segments (three protrusions)

[Source: researcher]
Similarly, the relative SPL trends for $\mathrm{N}=3$, and $\mathrm{N}=7$ are gradually descended. For the segments $\mathrm{N}=5,9$ the relative SPL are less than those for other odd numbers of segments, and its trends are disordered every $10 \mathrm{~m}$. The SPL attenuation at the end of street length for the $\mathrm{N}=7$ segments is $(-6 \mathrm{~dB})$ that can be considered a noticable value.

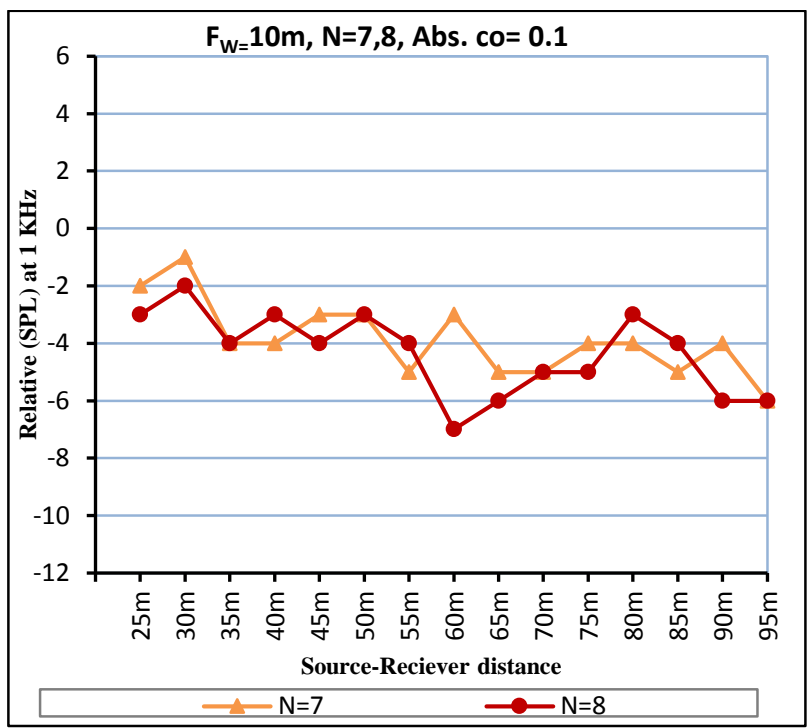

Figure 5 - Comparison between relative SPL in $N=7,8$ cases of façade's segments (four protrusions)

[Source: researcher]

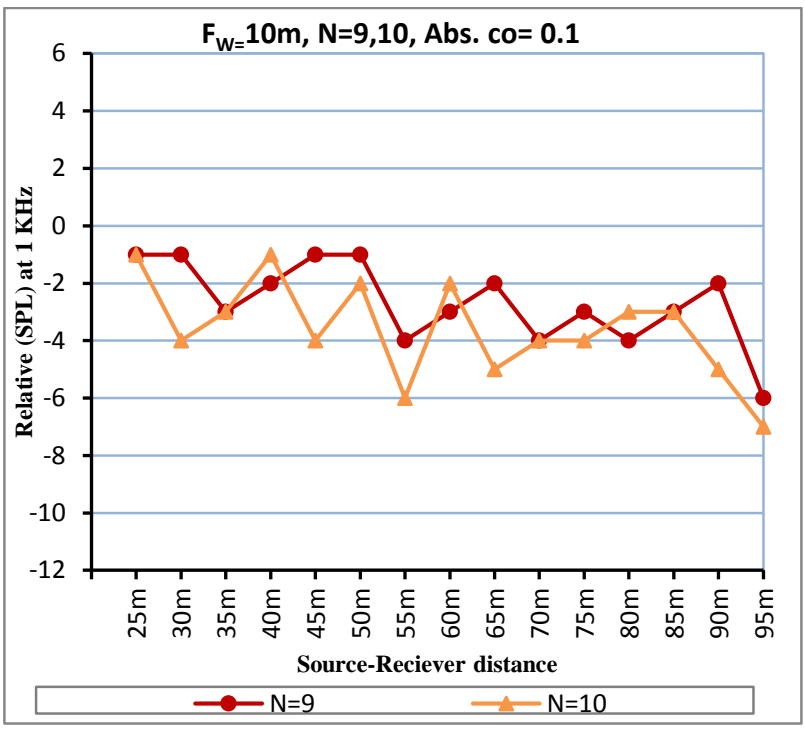

Figure 6 - Comparison between relative SPL in N=9,10 cases of façade's segments (five protrusions)

[Source: researcher] 
The analysis of dividing (10m) façade's width into two protrusions showed the number of segments $(\mathrm{N}=4)$ case in terms of Absorption co. $=(0.1)$ is better than $(\mathrm{N}=3)$ case in terms of sound attenuation. Also the case of $(\mathrm{N}=3)$ is beter than $(\mathrm{N}=2)$ case however its relative (SPL) is larger than $(\mathrm{N}=2)$ case, because it was gradually reduced sound without disorders.

With paying particular attention to the details of $(\mathrm{N}=4)$ case compared to $(\mathrm{N}=3)$ case as shown in Figure 7 , it was found that the effect of segments' width to depth ratio and distance of array have a significant role in decreasing sound pressure levels. In case of $(\mathrm{N}=4)$ the segments' width to depth was $(2 \mathrm{x}: \mathrm{x})$ where $(\mathrm{x}=1.25 \mathrm{~m})$ and distance of array is $(2 \mathrm{x})$, that lead to more decrease of the sound pressure level with distance from the source than in case of $(\mathrm{N}=3)$ where the segments' width to depth was $(2.5 \mathrm{x}: \mathrm{x})$ where $(\mathrm{x}=1.25 \mathrm{~m})$ and distance of array is (2.5x).

Hence, it was clear that the use of rhytmic tite array of small segments' protrusions on the façade is better than the use of rhytmic wide array of wide segments' protrusions on the façade along the same street length in terms of formation by two (break-out) protrusions, and the distance of array should not be more than twice the depth of segments (aray:depth ratio=2x:x/façade with two protrusions).

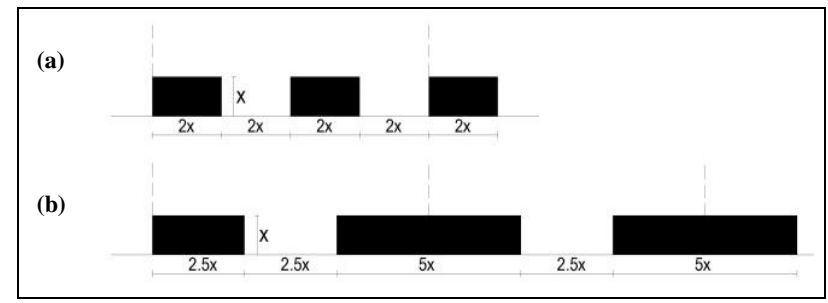

Figure 7 - (a) Focus on details of $N=4$ case (b) $N=3$ case [Source: researcher]

The analysis of dividing façade into four protrusions showed the number of segments $(\mathrm{N}=8)$ case in terms of Absorption co. $=(0.1)$ is better than $(\mathrm{N}=7)$ case. And with paying particular attention to the details of $(\mathrm{N}=8)$ case compared to $(\mathrm{N}=7)$ case as shown in Figure 8 , it was found that the effect of segments' width to depth ratio and distance of array have a similar result in decreasing sound pressure levels. But in case of $(\mathrm{N}=8)$ the segments' width to depth was $(\mathrm{x}: \mathrm{x})$ where $(\mathrm{x}=1.25 \mathrm{~m})$ and distance of array is ( $\mathrm{x})$, that lead to gradually decrease of the sound pressure level with distance from the source than in case of $(\mathrm{N}=7)$ where the segments' width to depth was $(1.1 \mathrm{x}: \mathrm{x})$ where $(\mathrm{x}=1.25 \mathrm{~m})$ and distance of array is $(1.1 \mathrm{x})$.

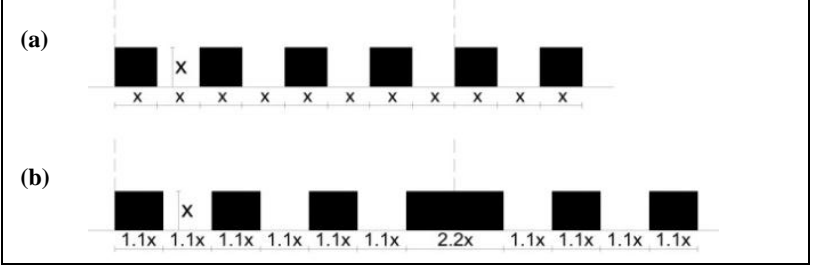

Figure 8 - (a) Focus on details of $N=8$ case (b) $N=7$ case [Source: researcher]

Hence, it was clear that the use of rhytmic tite array of small segments' protrusions on the façade along the street length is an effective formation by four (break-out) protrusions in case of the distance of array does not be more than the value of depth segments (array:depth ratio $=\mathrm{x}: \mathrm{x} /$ façade with four protrusions).

When focus on the details of $(\mathrm{N}=6)$ case compared to $(\mathrm{N}=5)$ case as shown in Figure 9, it was found that the effect of dividing façade width (10m) into three segments' protrusions has a disordered results in decreasing sound pressure levels. In case of $(\mathrm{N}=6)$ the segments' width to depth was $(1.3 \mathrm{x}: \mathrm{x})$ where $(\mathrm{x}=1.25 \mathrm{~m})$ and distance of array is $(1.3 \mathrm{x})$, and in case of $(\mathrm{N}=5)$ where the segments' width to depth was (1.6x:x) where distance of array is (1.6x), that lead to a chaotic decrease in sound pressure level with distance from the source, see Figure 4.

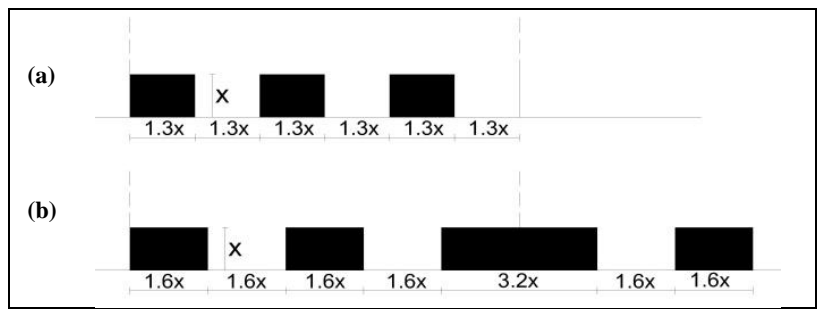

Figure 9- (a) Focus on details of $\mathrm{N}=6$ case (b) $\mathrm{N}=5$ case [Source: researcher]

When focus on the details of $(\mathrm{N}=10)$ case compared to $(\mathrm{N}=9)$ case as shown in, it was found that the effect of dividing façade width $(10 \mathrm{~m})$ into five segments' protrusions has a disordered results in decreasing sound pressure levels. In case of $(\mathrm{N}=10)$ the segments' width to depth was $(0.8 \mathrm{x}: \mathrm{x})$ where $(\mathrm{x}=1.25 \mathrm{~m})$ and distance of array is $(0.8 \mathrm{x})$, and in case of $(\mathrm{N}=9)$ where the segments' width to depth was $(0.9 \mathrm{x}: \mathrm{x})$ where distance of array is 
(0.9x), that lead to a chaotic decrease in sound pressure level with distance from the source, see Figure 6.

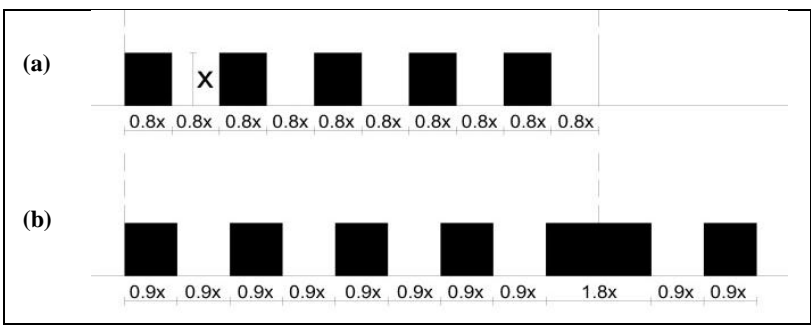

Figure 10- (a) Focus on details of $N=10$ case (b) $N=9$ case [Source: researcher]

As expected;by increasing the absorption coefficient, the sound attenuation in the best cases will increase, see Figure 11, Figure 12. Where absorpion coefficient is (0.3) the case of $(\mathrm{N}=4)$ can decrease sound by the end of the street to $(-10 \mathrm{~dB})$, and the case of $(\mathrm{N}=8)$ lead to decrease sound to $(-9 \mathrm{~dB})$. Where absorpion coefficient is $(0.5)$ the case of $(\mathrm{N}=8)$ can decrease sound by the end of the street to $(-11 \mathrm{~dB})$, and the case of $(\mathrm{N}=4)$ lead to decrease sound to $(-10 \mathrm{~dB})$.

Finally, The introduction of façade's formation by segments clearly has a significant role that lowers the sound pressure level. The decrease in sound pressure level with distance is much higher for the vertical segmented protrusions models in specific conditions than to its reference flat façade model.

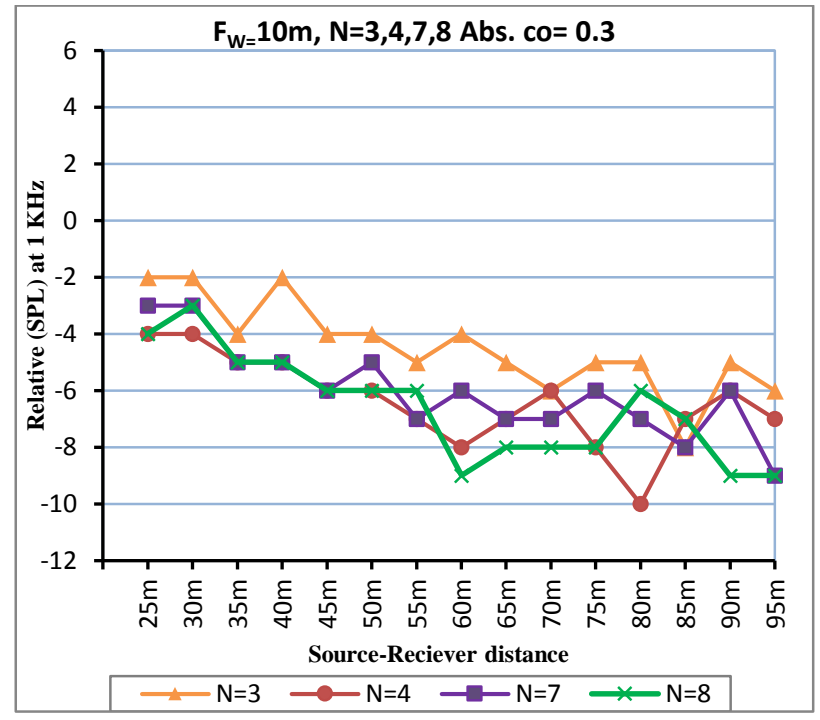

Figure 11- Comparison between relative $S P L$ in $\mathbf{N}=3,4,7,8$ cases of façade's segments (Abs. co. $=0.3$ )

[Source: researcher]

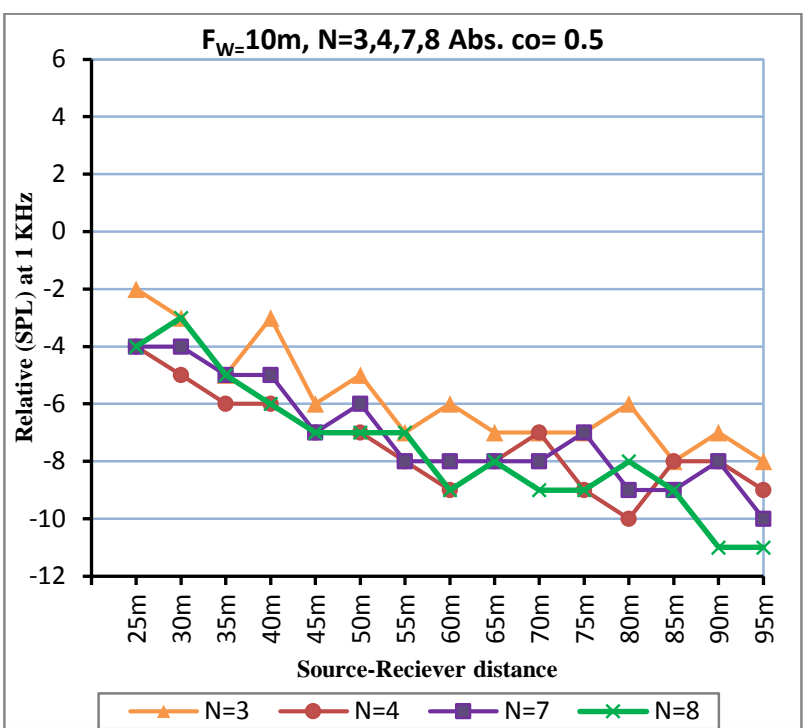

Figure 12- Comparison between relative $S P L$ in $N=3,4,7,8$ cases of façade's segments (Abs. co. $=0.5$ ) [Source: researcher]

\section{CONCLUSIONS}

In this work series of computer simulations of varied numbers of segments that form façades were investigated in order to evaluate the real effect of the diffusion reflections that happened by façades with formations; relative to the smooth façades on sound propagation in streets

The importance to divide façades into vertical segmented protrusions in simulation models was presented. The particular facade details by segmented protrusions increase the scattering of sound and lead to a stronger decrease of the sound pressure level with distance from the source, compared to fully flat facades.

The presence of vertical segmented protrusions formed the flat facades was shown to be a good solution to increase the diffusivity of the sound-field in a street at certain frequency sothat it decreases the sound pressure levels along the length.

The further studies should take into consider the role of façade's formation in noise propagation in varied configurations of urban streets. The focus view on façade's segments protrusions, and on the details are related to segments' array to segments' depth ratio that affect results in sound pressure levels along the street's length. 


\section{REFERENCES}

[1] E. Official, "Directive 2002/49/EC of the European Parliament and of the Council of 25 June, 2002 relative to the assessment and management of environmental noise Official J," Eur. Communities L, vol. 189.

[2] B. Berglund, T. Lindvall, and D. H. Schwela, "Guidelines for community noise," World Health Organization, (WHO), 1999.

[3] M. C. Mishra, "Study and development of road traffic noise model," THAPAR UNIVERSITY, 2010.

[4] W. Passchier-Vermeer, and W. Passchier, "Noise exposure and public health," Environ. Health Perspect, vol. 108(Suppl 1), pp. 123-131, 2000.

[5] "Noise: Health Effects and Controls," University of California, Berkeley, 2007.

[6] R. Schmid, "Aging nation faces growing hearing loss," CBS News, 2007.

[7] I. C. M. Guedes, S. R. Bertoli, and P. H. Zannin, "Influence of urban shapes on environmental noise: A case study in Aracaju-Brazil," Science of the Total Environment, vol. 412, pp. 66-76, 2011.

[8] L. T. Silva, M. Oliveira, and J. F. Silva, "Urban form indicators as proxy on the noise exposure of buildings," Applied Acoustics, vol. 76, pp. 366376, 2014.

[9] M. F. Oliveira, and L. T. Silva, "The influence of urban form in urban noise propagation."

[10] M. I. F. Oliveira, and L. T. Silva, "The influence of urban form on facades noise levels," 2011.

[11] A. Gidlöf-Gunnarsson, and E. Öhrström, "Noise and well-being in urban residential environments: The potential role of perceived availability to nearby green areas," Landscape and Urban Planning, vol. 83, no. 2, pp. 115-126, 2007.

[12] H.-S. Yang, "Outdoor noise control by natural/sustainable materials in urban areas," 2013.

[13] O. Umnova, K. Attenborough, and C. M. Linton, "Effects of porous covering on sound attenuation by periodic arrays of cylinders," The Journal of the Acoustical Society of America, vol. 119, no. 1, pp. 278-284, 2006.

[14] Z. Haron, D. Oldham, K. Yahya et al., "modeling of sound propagation in urban streets containing trees using markovian technique," Malaysian Journal of Civil Engineering, vol. 21, no. 1, pp. 55-68, 2009.

[15] J. Kang, "Sound propagation in street canyons: Comparison between diffusely and geometrically reflecting boundaries," The Journal of the Acoustical Society of America, vol. 107, no. 3, pp. 1394-1404, 2000.

[16] J. Picaut, J. Hardy, and L. Simon, "Sound propagation in urban areas: A periodic disposition of buildings," PHYSICAL REVIEW E, vol. 60, no. 4, 1999.

[17] M. R. Ismail, "A Parametric Study of the Effect of Building Distributions and Size on the Propagation of Sound in the Urban Environment," Architectural Engineering Technology, vol. 3, no. 1, 2014.

[18] T. Van Renterghem, and D. Botteldooren, "The importance of roof shape for road traffic noise shielding in the urban environment," Journal of Sound and Vibration, vol. 329, no. 9, pp. 14221434, 2010.

[19] J. Kang, Urban sound environment: CRC Press, 2006.

[20] J. Kang, "Sound propagation in interconnected urban streets: a parametric study," Environment and Planning B, vol. 28, no. 2, pp. 281-294, 2001.

[21] J. Picaut, and D. Scouarnec, "A numerical study of the use of acoustic diffusers to reduce noise in urban areas," Noise in the Built Environment, 2010.

[22] P. Thomas, L. Dragonetti, T. Van Renterghem et $a l .$, "Detailed analysis of the sound field in a scale model of a street canyon." pp. 1-4.

[23] J. Picaut, and L. Simon, "A scale model experiment for the study of sound propagation in urban areas," Applied Acoustics, vol. 62, no. 3, pp. 327-340, 2001.

[24] J. Picaut, T. Le Pollès, P. L'Hermite et al., "Experimental study of sound propagation in a street," Applied Acoustics, vol. 66, no. 2, pp. 149173, 2005. 